\title{
Ocorrência e fatores de risco associados à leptospirose em cães atendidos em hospital veterinário no semiárido paraibano
}

\author{
Occurrence and risk factors associated with leptospirosis in dogs attended in a veterinary \\ hospital in the semiarid of the Paraíba State, Northeast region of Brazil
}

\begin{abstract}
Sérgio Santos de AZEVEDO'; Annielle Regina Fonseca FERNANDES ${ }^{1}$; Inês Maria Barbosa Nunes QUEIROGA $^{1}$; Clebert José ALVES${ }^{1}$; Zenaide Maria de MORAIS ${ }^{2}$; Carolina de Sousa Américo Batista SANTOS $^{2}$; Sílvio Arruda VASCONCELLOS ${ }^{2}$

${ }^{1}$ Unidade Acadêmica de Medicina Veterinária do Centro de Saúde e Tecnologia Rural da, Universidade Federal de Campina Grande, Patos-PB, Brasil

${ }^{2}$ Departamento de Medicina Veterinária Preventiva e Saúde Animal da Faculdade de Medicina Veterinária e Zootecnia, Universidade de São Paulo, São Paulo-SP, Brasil
\end{abstract}

\begin{abstract}
Resumo
Investigou-se a ocorrência de leptospirose em cães da cidade de Patos, semiárido paraibano, e realizou-se um estudo de fatores de risco associados à infecção. Foram examinadas 152 amostras de soro sanguíneo de cães atendidos em hospital veterinário no período de julho a novembro de 2008. O diagnóstico da leptospirose foi realizado pela técnica de soroaglutinação microscópica, utilizando-se uma coleção de 24 sorovariedades. A frequência de animais soropositivos encontrada foi de 19,73\% (IC 95\% = 13,73\% - 26,96\%), e as sorovariedades mais frequentes foram Autumnalis (13,16\%) e Grippotyphosa (1,97\%). A análise de regressão logística múltipla mostrou que os fatores de risco para a leptospirose foram a não definição da raça (odds ratio = 3,67; $\mathrm{P}=0,009)$ e o contato com caprinos/ovinos (odds ratio $=10 ; \mathrm{P}=0,034)$.
\end{abstract}

Palavras-chave: Cães. Frequência. Leptospira spp. Sorologia.

\begin{abstract}
The occurrence of leptospirosis was investigated in dogs from Patos city, semiarid of Paraíba State, Northeast region of Brazil, and the risk factors associated with the infection were analyzed. One hundred and fifty two blood samples were collected from dogs attended in a veterinary hospital during July to November 2008. The diagnostic method carried out for leptospirosis was the microscopic agglutination test, using a batch of 24 leptospiral serovars. The frequency of seropositive animals was $19.73 \%(95 \% \mathrm{CI}=13.73 \%-26.96 \%)$ and most frequent reactant serovars were Autumnalis $(13.16 \%)$ and Grippotyphosa (1.97\%). The multivariate logistic regression analysis showed that the risk factors for leptospirosis were mixed breed (odds ratio $=3.67 ; \mathrm{P}=0.009)$ and the contact with caprine/ovine (odds ratio $=10 ; \mathrm{P}=$ $0.034)$.
\end{abstract}

Keywords: Dogs. Frequency. Leptospira spp. Serology.

\section{Introdução}

A leptospirose é uma zoonose bacteriana de curso agudo e crônico, de ocorrência endêmica e caráter sistêmico que afeta diversas espécies de animais domésticos, silvestres e os seres humanos, amplamente disseminada, assumindo considerável papel como problema econômico e de saúde pública ${ }^{1}$. Os surtos se reproduzem por exposição à água contaminada com urina ou tecidos provenientes de animais infectados ${ }^{2}$, particularmente nas ocasiões em que ocorrem elevados índices de precipitações pluviométricas, e nas regiões em que o solo apresenta reação neutra ou levemente alcalina, associando-se ainda à variedade de espécies hospedeiras que facilitam a cadeia de eventos necessários para a transmissão da doença.

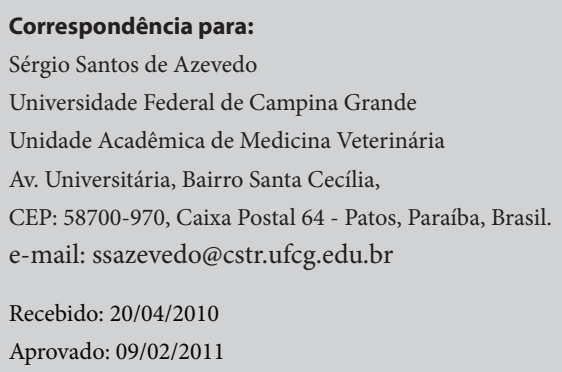


Dentre as modalidades de fontes de infecção dos animais acometidos, da maior relevância é o papel dos portadores (convalescentes e sadios), excretores de leptospiras a quem se atribui a persistência de fo$\cos$ da doença. Devido à longa duração desta condição e ampla facilidade de deslocamento, por não manifestar sinais clínicos de infecção, eles se tornam os reservatórios de manutenção do agente no ambiente ${ }^{2}$. Entre os animais domésticos, em nível urbano, a principal fonte de infecção da leptospirose humana são os cães, pois estes animais vivem em contato direto com os seres humanos e podem eliminar leptospiras vivas pela urina durante meses, mesmo sem apresentar nenhum sinal clínico ${ }^{1}$.

Os inquéritos sorológicos exercem um papel de relevância indiscutível no controle da infecção, pois permitem o conhecimento das diferentes sorovariedades existentes em determinada região ${ }^{1}$. Além dos resultados sorológicos é importante avaliar os fatores de risco aos quais os indivíduos estão expostos, o que permite um direcionamento racional de medidas de prevenção.

Tendo em vista a ampliação de informações acerca da epidemiologia da doença e a sua importância como zoonose, o objetivo do presente trabalho foi determinar a soroprevalência de anticorpos anti-Leptospira spp. em cães do semiárido paraibano e identificar fatores de risco associados à infecção.

\section{Material e Método}

A pesquisa foi realizada na cidade de Patos, $\mathrm{PB}$, cuja área territorial é de $513 \mathrm{~km}^{2}$, localizada na mesorregião do Sertão, semiárido paraibano, ficando situada a uma altitude de $242 \mathrm{~m}$ acima do nível do mar e a uma distância de $289 \mathrm{~km}$ da capital do Estado, João Pessoa. Possui clima quente e seco, com temperaturas médias anuais de $35^{\circ} \mathrm{C}$ no verão e 32 ${ }^{\circ} \mathrm{C}$ no inverno e precipitação pluviométrica anual de aproximadamente $700 \mathrm{~mm}^{3}$.
Foram utilizados 152 cães atendidos na rotina da Clínica de Pequenos Animais do Hospital Veterinário do Centro de Saúde e Tecnologia Rural (CSTR) da Universidade Federal de Campina Grande (UFCG), Campus de Patos, PB, durante o período de julho a novembro de 2008. Foram selecionados todos os animais com idade $\geq 6$ meses, com a autorização prévia do proprietário, seguindo uma rotina de dois dias semanais. A colheita de sangue foi efetuada por punção da veia cefálica utilizando-se seringas descartáveis de $10 \mathrm{~mL}$. As amostras de sangue foram centrifugadas a $3.500 \mathrm{rpm}$ por 10 minutos para obtenção do soro, o qual foi estocado a $-20{ }^{\circ} \mathrm{C}$ para posterior realização do diagnóstico sorológico da infecção por Leptospira spp. Os proprietários dos cães responderam a um questionário epidemiológico, elaborado de modo a fornecer dados com o intuito de verificar a ausência ou presença de algumas práticas e condições que atuem como possíveis fatores de risco para a leptospirose canina.

Para o diagnóstico sorológico da infecção por Leptospira spp., foi utilizada técnica de soroaglutinação microscópica ${ }^{4,5}$, com uma coleção de antígenos vivos que incluiu 24 sorovariedades de leptospiras: Australis, Bratislava, Autumnalis, Butembo, Castellonis, Bataviae, Canicola, Whitcombi, Cynopteri, Grippotyphosa, Hedomadis, Copenhageni, Icterohaemorrhagiae, Javanica, Panama, Pomona, Pyrogenes, Hardjo, Shermani, Tassarovi, Andamana, Patoc, Sentoc e Mini. Os soros foram triados na diluição de 1:100, e aqueles que apresentaram $50 \%$ ou mais de aglutinação foram titulados pelo exame de uma série de diluições geométricas de razão dois. O título do soro foi a recíproca da maior diluição que apresentou resultado positivo. Animais com título $\geq 100$ foram considerados positivos. Os antígenos eram examinados ao microscópio de campo escuro, previamente aos testes, a fim de verificar a mobilidade e a presença de auto-aglutinação ou de contaminantes.

A análise de fatores de risco foi efetuada em duas etapas: análise univariada e análise multivariada. $\mathrm{Na}$ 
análise univariada, as variáveis que apresentaram um valor de $\mathrm{p} \leq 0,2$ pelo teste de qui-quadrado ou teste exato de Fisher, quando indicado, foram selecionadas para a análise multivariada, utilizando-se a regressão logística múltipla ${ }^{6}$. A colinearidade entre as variáveis preditoras foi verificada por meio da análise de correlação e, para aquelas que apresentaram forte colinearidade (coeficiente de correlação $\geq 0,9$ ), uma das duas foi excluída da análise múltipla de acordo com a plausibilidade biológica. O nível de significância adotado na análise múltipla foi de $5 \%$. Todas as análises foram realizadas com o programa SPSS 13.0 for Windows.

\section{Resultados e Discussão}

Das 152 amostras de soros sanguíneos de cães analisadas, constatou-se que 30 apresentaram resultados positivos (título $\geq 100$ ), resultando em uma frequência de $19,74 \%$ (IC 95\% = 13,73\% - 26,96\%), com os títulos variando de 100 a 6.400 . As amostras positivas apresentaram reações para uma ou mais variantes sorológicas, predominando as reações para as sorovariedades Autumnalis (13,16\%) e Grippotyphosa $(1,97 \%)$. Também foram constatadas reações para as sorovariedades Castellonis (1,32\%), Icterohaemorrhagie (1,32\%), Australis (0,66\%), Hebdomalis $(0,66 \%)$ e Butembo $(0,66 \%)$ (Tabela 1$)$.

Em similaridade a este estudo, Aguiar et al. ${ }^{7}$ encontraram a sorovariedade Autumnalis como a mais pre- valente (22\%). Já Lopes et al. ${ }^{8}$ referiram que essa sorovariedade foi a segunda mais prevalente, com 19,12\% de reações positivas. A presença da sorovariedade $\mathrm{Au}-$ tumnalis causa preocupação, pois não existe imunidade cruzada entre as diferentes sorovariedades, e no mercado existem as vacinas compostas, basicamente, pelas sorovariedades Canicola, Icterohaemorrhagiae, Grippotyphosa e Pomona, o que reforça ainda mais a importância da pesquisa continuada no desenvolvimento de novas vacinas contra a leptospirose e a necessidade da inclusão de novas sorovariedades, visando à elaboração de vacinas mais efetivas e de imunidade mais duradoura.

A ocorrência da sorovariedade Grippotyphosa aponta a importância da população de roedores na transmissão da doença, visto que os roedores são os hospedeiros de manutenção dessa sorovariedade ${ }^{1}$, e reforça a necessidade de programas de controle de roedores, adotando, além das medidas ofensivas (desratização), normalmente as únicas utilizadas, a inclusão de modificações ambientais como medidas preventivas e a educação em saúde. Os ratos e, em especial, as ratazanas, tidos como os principais portadores universais das leptospiras, são considerados um dos principais responsáveis pela transmissão da doença ao homem.

A ausência de reações para a sorovariedade Canicola no presente trabalho surpreende, pois a mesma

Tabela 1 - Frequência de aglutininas anti-Leptospira spp. em 152 amostras de soro de cães atendidos em hospital veterinário em Patos, semiárido paraibano, segundo a sorovariedade e seus respectivos títulos, no período de julho a novembro de 2008

\begin{tabular}{lcccccccc}
\hline \multirow{2}{*}{ Sorovariedade } & \multicolumn{7}{c}{ Título } & Total (\%) \\
\cline { 2 - 7 } & 100 & 200 & 400 & 800 & 1600 & 3200 & 6400 & $20(13,16)$ \\
\hline Autumnalis & 3 & 7 & 2 & 2 & 3 & 1 & 2 & $3(1,97)$ \\
Grippotyphosa & 0 & 0 & 2 & 0 & 0 & 1 & 0 & $2(1,32)$ \\
Castellonis & 0 & 1 & 1 & 0 & 0 & 0 & 0 & $2(1,32)$ \\
Icterohaemorrhagiae & 2 & 0 & 0 & 0 & 0 & 0 & 0 & $1(0,66)$ \\
Australis & 0 & 0 & 1 & 0 & 0 & 0 & 0 & $1(0,66)$ \\
Hebdomadis & 0 & 0 & 1 & 0 & 0 & 0 & 0 & $1(0,66)$ \\
Butembo & 1 & 0 & 0 & 0 & 0 & 0 & 0 &
\end{tabular}


é reconhecidamente a mais encontrada em cães ${ }^{1}$. Este achado concorda com Alves et al. ${ }^{9}$, que também realizaram um estudo na cidade de Patos e não encontraram animais positivos para essa sorovariedade. Já Batista et al. ${ }^{10}$ referiram que a sorovariedade Canicola foi apontada como a terceira mais prevalente em cães do município de Campina Grande, PB. Esse fato pode ser atribuído à utilização de vacinas antileptospirose em cães da cidade de Patos, visto que 47 dos animais atendidos foram vacinados contra leptospirose (dado coletado com o questionário), o que representa $30,92 \%$ dos animais.

Foram observadas reações sorológicas para sorovariedades consideradas acidentais para cães, como Australis e Hebdomadis. Segundo Bolin ${ }^{11}$, em determinadas regiões, diferentes sorovariedades de leptospiras são prevalentes e são associadas a um ou mais hospedeiros de manutenção que servem de reservatórios da infecção, e são geralmente espécies silvestres e, algumas vezes, animais domésticos e de produção. A transmissão entre os mesmos pode ser eficiente, e a incidência da infecção é relativamente alta. $\mathrm{O}$ contato com os hospedeiros de manutenção ou áreas contaminadas com urina desses pode causar infecção em outras espécies.

$\mathrm{Na}$ análise univariada (Tabela 2), as variáveis selecionadas foram a não definição da raça, contato com caprinos/ovinos e não viajar com o animal. A não definição da raça (odds ratio $=3,67$ ) e o contato com caprinos/ovinos (odds ratio $=10$ ) foram apontados como fatores de risco para a infecção por Leptospira spp. pela regressão logística múltipla (Tabela 3).

A não definição da raça como fator de risco para a leptospirose também foi citado por Batista et al. ${ }^{10}$

Tabela 2 - Distribuição das variáveis analisadas como possíveis fatores de risco para a leptospirose em 152 cães atendidos em hospital veterinário em Patos, semiárido paraibano, no período de julho a novembro de 2008

\begin{tabular}{lccc}
\hline \multicolumn{1}{c}{ Variáveis } & Expostos/soropositivos & Expostos/soronegativos & $\mathrm{p}$ \\
\hline Proprietário com 1o grau incompleto & $9 / 30$ & $27 / 122$ & 0,320 \\
Animal ser macho & $17 / 30$ & $67 / 122$ & 1,000 \\
Idade do animal $\geq 4$ anos & $9 / 30$ & $23 / 122$ & 0,686 \\
Animal sem raça definida & $22 / 30$ & $60 / 122$ & $0,030^{*}$ \\
Animal com acesso irrestrito à rua & $3 / 30$ & $6 / 122$ & 0,222 \\
Alimentar os animais com restos de comida & $2 / 30$ & $2 / 122$ & 0,400 \\
Contato com outros cães & $19 / 30$ & $65 / 122$ & 0,431 \\
Contato com bovinos & $1 / 30$ & $1 / 122$ & 0,357 \\
Contato com equinos & $26 / 30$ & $102 / 122$ & 0,680 \\
Contato com gatos & $7 / 30$ & $22 / 122$ & 0,687 \\
Contato com caprinos/ovinos & $2 / 30$ & $2 / 122$ & $0,175^{*}$ \\
Contato com animais silvestres & $3 / 30$ & $9 / 122$ & 0,705 \\
Ambiente do animal composto por terra & $10 / 30$ & $36 / 122$ & 0,916 \\
Não realizar limpeza do ambiente onde o animal vive & $2 / 30$ & $7 / 122$ & 1,000 \\
Não realizar limpeza semanal do ambiente onde o animal vive & $7 / 30$ & $26 / 122$ & 0,810 \\
Não vacinar os animais (qualquer vacina) & $7 / 30$ & $22 / 122$ & 0,483 \\
Passear com o animal & $22 / 30$ & $82 / 122$ & 0,669 \\
Viajar com o animal & $28 / 30$ & $99 / 122$ & $0,167^{*}$ \\
Presença de roedores no domicílio & $18 / 30$ & $68 / 122$ & 0,829 \\
Contato com açudes & $7 / 30$ & $20 / 122$ & 0,532 \\
\hline * Varianves
\end{tabular}

* Variáveis selecionadas para a regressão logística múltipla $(\mathrm{P} \leq 0,2)$ 
Tabela 3 - Fatores de risco para a leptospirose em cães atendidos em hospital veterinário em Patos, semiárido paraibano, determinados por regressão logística múltipla, no período de julho a novembro de 2008

\begin{tabular}{cccc}
\hline Fator de risco & Odds ratio & IC 95\% & P \\
\hline Raça não definida & 3,67 & $1,39-9,68$ & 0,009 \\
Contato com caprinos/ovinos & 10 & $1,19-84,32$ & 0,034 \\
\hline
\end{tabular}

na cidade de Campina Grande, PB. Animais sem raça definida, geralmente, têm mais acesso à rua, o que aumenta o risco de exposição às leptospiras. Em estudo epidemiológico conduzido em Buenos Aires, o acesso à rua também foi apontado como fator de risco $^{12}$. Deve-se considerar que este tipo de manejo pode propiciar inúmeras possibilidades de infecção pelo contato direto ou indireto com outros animais ou através do acesso a áreas alagadiças.

O contato com caprinos/ovinos como fator de risco é muito plausível uma vez que a transmissão da doença se dá de forma direta ou indireta e é fato comum na cidade de Patos, principalmente na periferia, a ocorrência de caprinos/ovinos criados soltos, o que de certa forma pode garantir o risco de contato desses animais com os cães. Some-se a isso o fator de que diversos estudos recentes realizados no Brasil apontam para a ocorrência de anticorpos antileptospiras em caprinos e ovinos ${ }^{13,14,15,16}$, bem como o isolamento do agente ou identificação do DNA por PCR ${ }^{17,18,19}$.

Estudos conduzidos em caprinos e ovinos no semiárido nordestino apontaram predominância de reações para a sorovariedade Autumnalis. Araújo Neto ${ }^{15}$ utilizou 100 ovelhas abatidas no matadouro público

\section{Referências}

1.FAINE, S.; ADLER, B.; BOLIN, C.; PEROLAT, P. Leptospira and leptospirosis. 2. ed. Melbourne: MedSci, 1999. 272 p.

2. VASCONCELLOS, S. A. Leptospirose animal. In: ENCONTRO NACIONAL EM LEPTOSPIROSE, 3., 1993, Rio de Janeiro. Anais... Rio de Janeiro: Ministério da Saúde, Instituto Oswaldo Cruz, Fundação Nacional de Saúde, 1993. p. 62-65.

3. BRASIL. Instituto Brasileiro de Geografia e Estatística. Cidades@. Brasília, 2007. Disponível em: <http://www.ibge. gov.br/cidadesat/topwindow.htm?1>. Acesso em: 27 set. 2009. de Patos, $\mathrm{PB}$, para o isolamento da bactéria a partir do trato genital, realizando paralelamente a sorologia, obtendo $9 \%$ de soropositividade para a doença, e $44,4 \%$ de frequência para a sorovariedade Autumnalis. Higino ${ }^{16}$ realizou a sorologia de 80 ovinos e obteve $7,5 \%$ de positividade, com $83,3 \%$ de frequência para a sorovariedade Autumnalis. Esses estudos, bem como os resultados do presente trabalho, levantam a hipótese dos caprinos/ovinos como fontes de infecção da sorovariedade Autumnalis na região e reforçam o risco de exposição de cães ao agente pelo contato com esses animais.

\section{Conclusões}

Os cães atendidos em hospital veterinário da cidade de Patos -,PB estavam expostos a várias sorovariedades de Leptospira spp., com maiores preocupações em cães sem raça definida e que tiveram contato com caprinos e/ou ovinos.

\section{Agradecimentos}

Ao Conselho Nacional de Desenvolvimento Científico e Tecnológico (CNPq) pela bolsa de iniciação científica concedida a Annielle Regina Fonseca Fernandes.

4. GALTON, M. M.; SULZER, C. R.; SANTA ROSA, C. A.; FIELDS, M. J. Aplication of a microtecnique to the aglutination test for leptospiral antibodies. Applied Microbiology, v. 13, p. $81-85,1965$

5. COLE, J. R.; SULZER, C. R.; PURSELL, A. R. Improved microtechnique for the leptospiral microscopic agglutinaton test. Applied Microbiology, v. 25, p. 976-980, 1973.

6. HOSMER, D. W.; LEMESHOW, S. Applied logistic regression. New York: John Wiley \& Sons, 2000. 375 p. 
7. AGUIAR, D. M.; CAVALCANTE, G. T.; MARVULO, M. F. V.; SILVA, J. C. R.; PINTER, A.; VASCONCELLOS, S. A.; MORAIS, Z. M.; LABRUNA, M. B.; CAMARGO, L. M. A.; GENNARI, S. M. Fatores de risco associados à ocorrência de anticorpos anti-Leptospira spp. em cães do município de Monte Negro, Rondônia, Amazônia Ocidental Brasileira. Arquivo Brasileiro de Medicina Veterinária e Zootecnia, v. 59, p. 70-76, 2007.

8. LOPES, A. L. S.; SILVA, W. B.; PADOVANI, C. R.; LANGONI, H.; MODOLO, J. R. Frequência sorológica antileptospírica em cães: sua correlação com roedores e fatores ambientais, em área territorial urbana. Arquivos do Instituto Biológico, v. 72, p. 289-296, 2005.

9. ALVES C. J.; ANDRADE, J. S. L.; VASCONCELLOS, S. A.; MORAIS, Z. M.; AZEVEDO, S. S.; SANTOS, F. A. Avaliação dos níveis de aglutininas anti-leptospira em cães no município de Patos-PB, Brasil. Revista Brasileira de Ciência Veterinária, v. 7 , n. 2, p. 17-21, 2000.

10. BATISTA, C. S. A.; AZEVEDO, S. S.; VASCONCELLOS, S. A.; MORAIS, Z. M.; CLEMENTINO, I. J.; ALVES, F. A. L.; LIMA, F. S.; ARÚJO NETO, J. O. Soroprevalência e fatores de risco para a leptospirose em cães de Campina Grande, Paraíba. Arquivo Brasileiro de Medicina Veterinária e Zootecnia, v. 57, p. 179-185, 2005.

11. BOLIN, C. A. Diagnosis of leptospirosis: A reemerging disease of companion animals. Seminars in Veterinary Medicine and Surgery (Small Animal), v. 11, p. 166-171, 1996.

12.RUBEL, D.; SEIJO, A.; CERNIGOI, B.; VIALE, A.; WISNIVESKY-COLLI, C. Leptospira interrogans en una población canina del gran Buenos Aires: variables asociadas com la seropositividad. Revista Panamericana de Salud Publica, v. 2, p. 102-105, 1997.
13.FAVERO, A. C. M.; PINHEIRO, S. R.; VASCONCELLOS, S. A.; MORAIS, Z. M.; FERREIRA, F.; FERREIRA NETO, J. S. Sorovares de leptospiras predominantes em exames sorológicos de bubalinos, ovinos, caprinos, equinos suínos e cães de diversos estados brasileiros. Ciência Rural, v. 32, p. 613-619, 2002.

14.SCHMIDT, V.; AROSI, A.; SANTOS, A. R. Levantamento sorológico da leptospirose em caprinos leiteiros no Rio Grande do Sul, Brasil. Ciência Rural, v. 32, p. 609-612, 2002.

15. ARAÚJO NETO, J. O. Isolamento de Leptospira spp. a partir do trato genital de ovelhas abatidas no matadouro público de Patos-PB, Estado da Paraíba, Brasil. 2005. 58 f. Monografia (Graduação em Medicina Veterinária) - Universidade Federal de Campina Grande, Patos, Paraíba, 2005.

16. HIGINO, S. S. Isolamento de Leptospira spp. a partir do trato geniturinário de ovinos abatidos no Matadouro Público de Patos, Estado da Paraíba, Brasil. 2007. 44 f. Monografia (Graduação em Medicina Veterinária) - Universidade Federal de Campina Grande, Patos, Paraíba, 2007.

17. SILVA, E. F.; BROD, C. S.; CERQUEIRA, G. M.; BOURSCHEIDT, D.; SEYFFERT, N.; QUEIROZ, A.; SANTOS, C. S.; KO, A. I.; DELLAGOSTIN, O. A. Isolation of Leptospira noguchii from sheep. Veterinary Microbiology, v. 121, p. 144-149, 2007.

18.LILENBAUM, W.; VARGES, R.; BRANDAO, F. Z.; CORTÊZ, A.; SILVA, S. O. S.; BRANDÃO, P. E.; RICHTZENHAIN, L. J.; VASCONCELLOS, S. A. Detection of Leptospira spp. in semen and vaginal fluids of goats and sheep by polymerase chain reaction. Theriogenology, v. 69, p. 837-842, 2008.

19.LILENBAUM, W.; VARGES, R.; RISTOW, P.; CORTÊZ, A.; SOUZA, S. O.; RICHTZENHAIN, L. J.; VASCONCELLOS, S. A. Identification of Leptospira spp. carriers among seroreactive goats and sheep by polymerase chain reaction. Research in Veterinary Science, v. 87, p. 16-19, 2009. 